\title{
Prognostic value of pretransplant FDG-PET in refractory/relapsed Hodgkin lymphoma treated with autologous stem cell transplantation: systematic review and meta-analysis
}

\author{
Hugo J. A. Adams ${ }^{1}$. Thomas C. Kwee ${ }^{1}$
}

Received: 13 October 2015 / Accepted: 14 February 2016/Published online: 2 March 2016

(C) The Author(s) 2016. This article is published with open access at Springerlink.com

\begin{abstract}
This study aimed to systematically review the prognostic value of pretransplant ${ }^{18} \mathrm{~F}$-fluoro-2-deoxy-D-glucose positron emission tomography (FDG-PET) in refractory/ relapsed Hodgkin lymphoma treated with autologous stem cell transplantation (SCT). MEDLINE was systematically searched for appropriate studies. Included studies were methodologically appraised. Results of individual studies were meta-analyzed, if possible. Eleven studies, comprising a total of 745 refractory/relapsed Hodgkin lymphoma patients who underwent FDG-PET before autologous SCT, were included. The overall methodological quality of these studies was moderate. The proportion of pretransplant FDG-PET positive patients ranged between 25 and $65.2 \%$. Progression-free survival ranged between 0 and $52 \%$ in pretransplant FDG-PET positive patients, and between 55 and $85 \%$ in pretransplant FDG-PET negative patients. Overall survival ranged between 17 and $77 \%$ in pretransplant FDG-PET positive patients, and between 78 and $100 \%$ in FDG-PET negative patients. Based on five studies that provided sufficient data for meta-analysis, pooled sensitivity and specificity of pretransplant FDG-PET in predicting treatment failure (i.e., either progressive, residual, or relapsed disease) were $67.2 \%$ (95\% confidence interval [CI] 58.2-75.3\%) and 70.7\% (95\% CI 64.2-76.5\%), respectively. Based on two studies that provided sufficient data for meta-analysis, pooled sensitivity and specificity of pretransplant FDG-PET in predicting death during follow-up were $74.4 \%$ (95\% CI 58.8-86.5\%) and 58.0\% (95\% CI 49.3-66.3\%),
\end{abstract}

Hugo J. A. Adams

h.j.a.adams@gmail.com

1 Department of Radiology and Nuclear Medicine, University Medical Center Utrecht, Heidelberglaan 100, 3584

CX Utrecht, The Netherlands respectively. In conclusion, the moderate quality evidence suggests pretransplant FDG-PET to have value in predicting outcome in refractory/relapsed Hodgkin lymphoma patients treated with autologous SCT. Nevertheless, a considerable proportion of pretransplant FDG-PET positive patients remains disease free and a considerable proportion of pretransplant FDG-PET negative patients develops disease relapse after autologous SCT.

Keywords Autologous stem cell transplantation · FDG-PET · Hodgkin lymphoma $\cdot$ Meta-analysis $\cdot$ Systematic review

\section{Introduction}

More than $90 \%$ of patients with limited-stage and up to $80 \%$ of patients with advanced-stage Hodgkin lymphoma achieve long-term disease-free survival with standard first-line therapies [1]. Unfortunately, a non-negligible fraction of Hodgkin lymphoma patients develops refractory/relapsed disease. Randomized trials have demonstrated the potential benefit of salvage chemotherapy followed by consolidation with highdose therapy (HDT) and autologous stem cell transplantation (SCT) as second-line therapy [2,3]. With this treatment regimen, more than $50 \%$ of patients can be cured [2-6]. Patients who relapse after HDT and autologous SCT have dismal outcomes [7, 8]. Timely identification of non-responders to standard second-line therapy is crucial to offer them the opportunity to switch to more intensive and potentially more effective therapies such as extended salvage therapy, additional radiation therapy, allogeneic SCT, tandem SCT, or the addition of recently developed novel drugs such as brentuximab vedotin. Several parameters have proven to be predictive of poor outcome in patients with relapsed Hodgkin lymphoma, including presalvage anemia, hypoalbuminemia, lymphopenia, presence of B symptoms, extranodal involvement at relapse, 
Karnofsky score $<90 \%$, and a time interval between first-line therapy and relapse detection of less than 1 year [4, 9-12]. Another method that might provide prognostic information is

${ }^{18}$ F-fluoro-2-deoxy-D-glucose positron emission tomography (FDG-PET). FDG-PET is widely used for staging Hodgkin lymphoma [13, 14], but may also be performed during treatment to identify non-responders. In newly diagnosed Hodgkin lymphoma, FDG-PET after 1-4 cycles of first-line therapy has shown to have prognostic value, although results are heterogeneous among different studies [15]. Over the past few years, several studies have also evaluated the prognostic value of pretransplant FDG-PET in refractory/relapsed Hodgkin lymphoma patients undergoing autologous SCT. However, there may be variability among individual studies with regard to internal validity (i.e., risk of bias) and external validity (i.e., generalizability of study results). A systematic review and meta-analysis are required to better comprehend the value of FDG-PET in this setting. The purpose of this study was therefore to systematically review and meta-analyze published data on the prognostic value of pretransplant FDG-PET in patients with refractory/relapsed Hodgkin lymphoma treated with salvage therapy, HDT, and autologous SCT.

\section{Materials and methods}

\section{Search strategy}

Medline was searched using the PubMed interface for original studies on the prognostic value of pretransplant FDG-PET in refractory/relapsed Hodgkin lymphoma, from start date to 12 July 2015. The search strategy is displayed in Table 1. References of the included studies were scrutinized for suitable references that were not retrieved by the initial PubMed search.

\section{Study selection}

Original studies reporting on the value of pretransplant FDGPET in predicting patient outcome (either number of progressive, residual, or relapsed diseases, number of deaths, progression-free survival, or overall survival) in refractory/

Table 1 Medline search performed using the PubMed interface on 12 July 2015

\begin{tabular}{|c|c|c|}
\hline No. & Search string & $\begin{array}{l}\text { No. of hits } \\
\text { in Medline }\end{array}$ \\
\hline 1. & $\begin{array}{l}\text { Fluorodeoxyglucose or 2-fluoro-2-deoxy-D-glucose } \\
\text { or FDG or 18F-FDG or positron emission } \\
\text { tomography or PET }\end{array}$ & 89,372 \\
\hline 2. & Hodgkin or Hodgkin's or Hodgkins & 81,948 \\
\hline 3. & No. 1 and no. 2 & 1768 \\
\hline
\end{tabular}

relapsed Hodgkin lymphoma treated with salvage therapy, HDT, and autologous SCT were eligible for inclusion. Studies were excluded if not written in English, Spanish, French, German, Italian, or Dutch. Articles without original patient data, such as reviews, editorials, letters, and conferences abstracts, were excluded. Articles with less than 10 patients and articles from which the same patient data were used in a more recent article were also excluded. Articles in which patients with Hodgkin lymphoma could not be separated from patients with other lymphoma subtypes, articles in which patients receiving allogeneic SCT could not be separated from patients receiving autologous SCT, and articles in which patients undergoing FDG-PET could not be separated from patients who were examined with other imaging techniques (e.g., gallium scans) were excluded. Articles in which therapy was modified on the basis of the pretransplant FDG-PET result (except for patients who were allocated to another salvage regimen in case of evident non-response or disease progression during salvage treatment, which is considered reflective of clinical practice) were not included into the main analysis, but addressed separately. Titles and abstracts of all studies that were obtained by the PubMed search were screened using these inclusion and exclusion criteria. Articles that were certainly ineligible were excluded at this stage. The remaining articles were then retrieved in full-text format to make a final decision as to whether they met the criteria to be included in this systematic review and meta-analysis.

\section{Methodological quality assessment}

The Quality in Prognosis Studies (QUIPS) criteria were used to assess the methodological quality of included studies [16]. The QUIPS criteria include six different domains: risk of bias in study participation ("do the study data available [i.e., patients not lost to follow-up] adequately represent the study sample?"), prognostic factor measurement ("is the prognostic factor measured in a similar way for all participants?"), outcome measurement ("is the outcome of interest measured in a similar way for all participants?"), study confounding ("have important potential confounding factors appropriately been accounted for?"), and statistical analysis and reporting ("is the statistical analysis appropriate, and are all primary outcomes reported") [16]. Risk of bias was scored as low, moderate, or high for each of these six domains [16].

\section{Meta-analysis}

Studies were eligible for meta-analysis if they provided sufficient data to construct $2 \times 2$ contingency tables to calculate the sensitivity and specificity of pretransplant FDG-PET in predicting treatment failure (i.e., either progressive, residual, or relapsed disease) and/or death during follow-up. This metaanalysis did not include studies that applied pretransplant 
FDG-PET-adapted therapies. To explore whether using different thresholds in studies included may have affected sensitivity or specificity, Spearman $\rho$ (comparison of the logit of the sensitivity and logit of 1 -specificity) was calculated. Spearman $\rho>0.6$ was considered to demonstrate the presence of a threshold effect [17]. If a threshold effect was absent, summary estimates of sensitivity and specificity were calculated, using the DerSimonian and Laird method [18]. The Higgins and Thompson test was used to assess heterogeneity in diagnostic odds ratios (DORs) across individual studies [19]. Heterogeneity was defined as $I^{2}$ exceeding $50 \%$. The DOR is an overall measure of accuracy of a diagnostic test that is not dependent of the threshold value or disease prevalence [20].

\section{Results}

\section{Literature search}

The Medline search revealed 1768 articles (Table 1). After screening titles and abstracts, 30 remained. Of these, 5 were excluded because these studies did not allow separate data extraction of patients with Hodgkin lymphoma from those with other non-Hodgkin lymphoma subtypes, 3 were excluded because these studies included less than 10 patients with Hodgkin lymphoma, 3 were excluded because these studies reported insufficient data about the prognostic consequences of the pretransplant FDG-PET status, 2 were excluded because these studies mixed pretransplant FDG-PET and gallium scan findings, 1 was excluded because patients undergoing autologous SCT could not be separated from patients undergoing allogeneic SCT, 1 was excluded because only patients with complete remission at pretransplant FDG-PET were included, and 1 was excluded because it included a group of patients that was treated without SCT and who could not be separated from patients undergoing autologous SCT. Finally, 14 articles, of which 11 did not change the therapy on the basis of the pretransplant FDG-PET results, and 3 applied pretransplant FDG-PET-adapted therapy, were included. The characteristics of these studies are displayed in Tables 2 and 3.

\section{Methodological quality}

The methodological quality assessment using the QUIPS criteria is displayed in Table 4. Overall, the methodological quality was moderate. There was moderate risk of bias for the domain of study inclusion in six studies, because five studies $[22,23,25,26,29]$ did not report whether refractory/relapsed disease was histologically confirmed before initiation of salvage therapy and one study [24] reported that refractory/ relapsed disease was not histologically verified in 50/141 patients. There was moderate risk of bias for the domain of prognostic factor measurement in six studies, because four studies did not report the whether a stand-alone PET system or integrated PET/CT system was used [21-23, 34], and two studies [24, 29] included patients who underwent stand-alone FDG-PET. In addition, there was high risk of bias for the domain of prognostic factor measurement in three studies [27, 30, 31], because these studies used stand-alone FDGPET systems and did not use standardized international FDG-PET interpretation criteria. There was moderate risk of bias in all 14 included studies, because none of these studies reported that refractory/relapsed disease after autologous SCT was histologically verified. Finally, there was moderate risk of bias for study confounding in 12 of 14 studies [21-28, 30, 32-34], because these studies included patients treated with heterogeneous treatment regimens.

\section{Prognostic value pretransplant FDG-PET}

Results of the 11 studies on the prognostic value of pretransplant FDG-PET are shown in Table 5. The proportion of pretransplant FDG-PET positive patients ranged between 25 and $65.2 \%$. Progression-free survival ranged between 0 and $52 \%$ in pretransplant FDG-PET positive patients, and between 55 and $85 \%$ in pretransplant FDG-PET negative patients. Overall survival ranged between 17 and $77 \%$ in pretransplant FDG-PET positive patients, and between 78 and $100 \%$ in FDG-PET negative patients.

Based on five studies that provided sufficient data for metaanalysis, pooled sensitivity and specificity of pretransplant FDG-PET in predicting treatment failure (i.e., either progressive, residual, or relapsed disease) were $67.2 \%$ (95\% confidence interval [CI] 58.2-75.3\%) and 70.7\% (95\% CI 64.2$76.5 \%$ ), respectively. Note that there was no threshold effect (Spearman $\rho=0.6, P=0.285$ ) and no heterogeneity in DORs among these five studies $\left(I^{2}=0.0 \%\right)$.)

Based on two studies that provided sufficient data for metaanalysis, pooled sensitivity and specificity of pretransplant FDG-PET in predicting death were $74.4 \%$ (95\% CI 58.8$86.5 \%$ ) and $58.0 \%$ (95\% CI 49.3-66.3\%), respectively. Note that the presence of a threshold effect and heterogeneity in DORs could not statistically be assessed with only two studies.

\section{Pretransplant FDG-PET-adapted therapeutic studies}

Three studies were included that applied FDG-PET-adapted therapy. Two studies $[32,34]$ directed the therapy in a systematic fashion (applied extended lines of salvage therapy in FDG-PET positive patients) and showed that patients who acquired FDG-PET negative status after extended lines of salvage therapy (91 and $\pm 80 \%$, respectively) had a similar PFS as those who acquired FDG-PET negative status after standard therapy (92\% and $\pm 80,[32,34]$. On the other hand, 


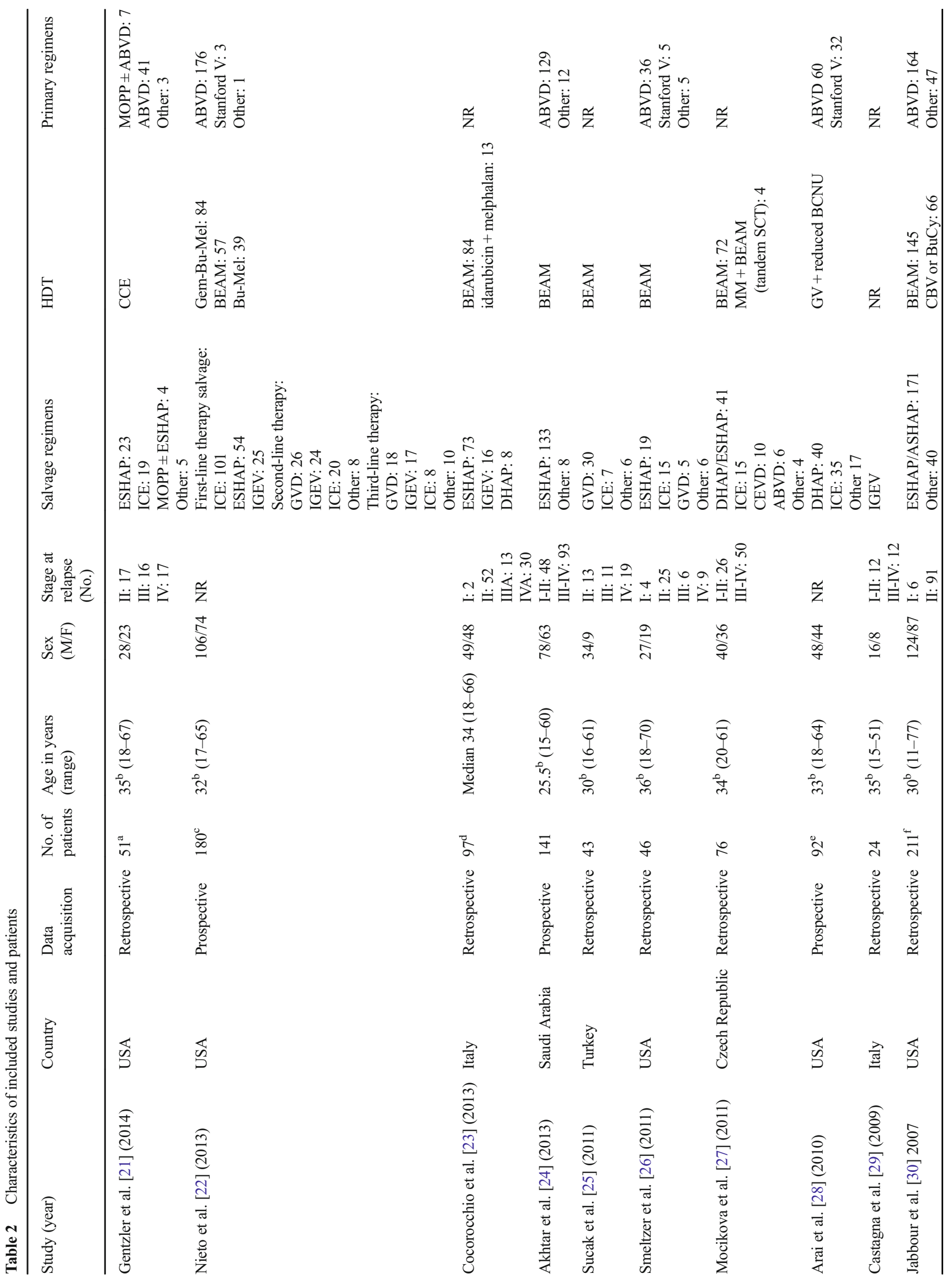




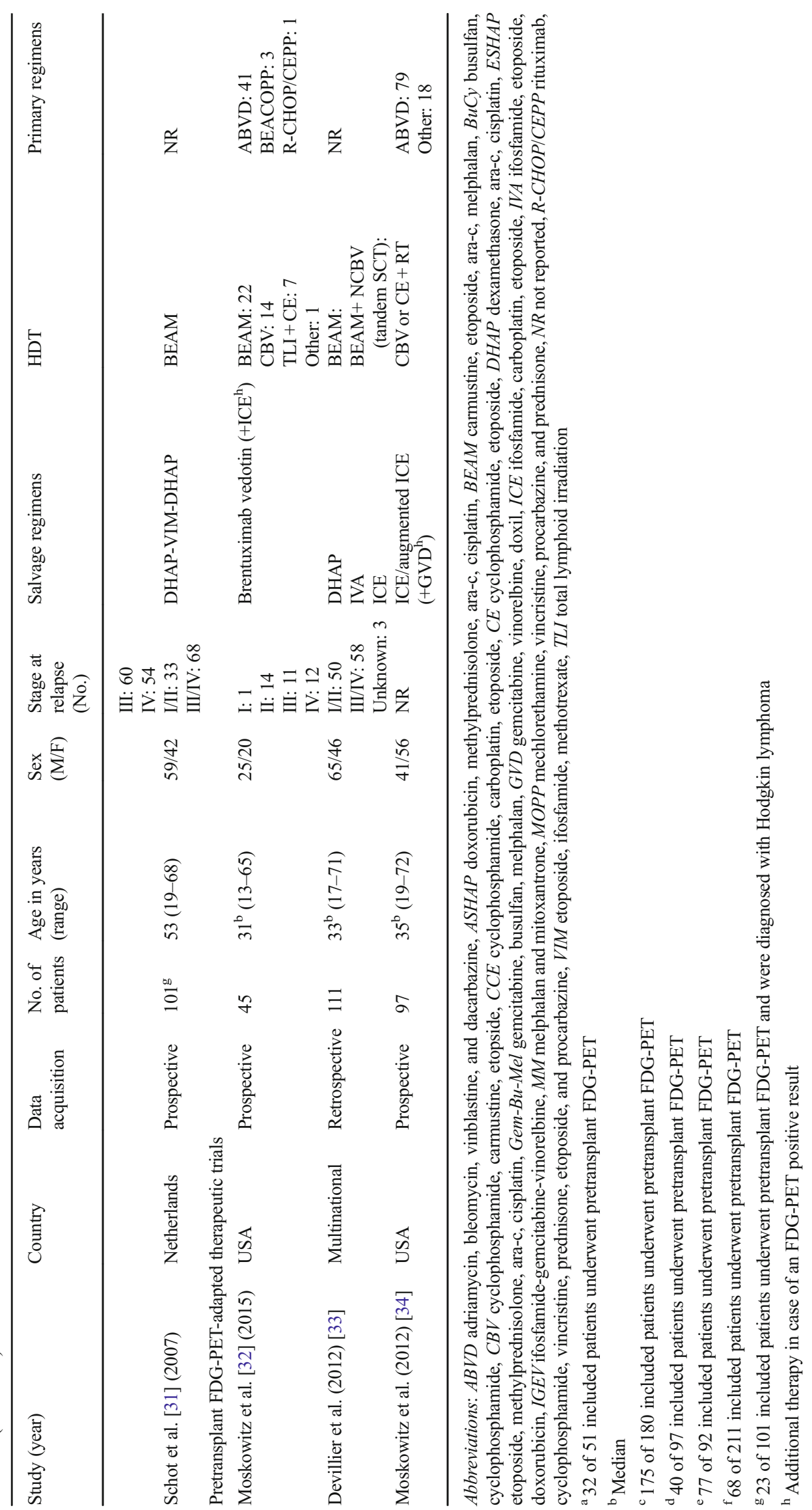


Table 3 FDG-PET imaging and interpretation methods, and criteria for treatment failure that were used in the included studies

\begin{tabular}{|c|c|c|c|c|}
\hline Study (year) & Imaging system(s) & Interpreters & $\begin{array}{l}\text { Histological verification } \\
\text { of relapse/refractory } \\
\text { disease before salvage } \\
\text { therapy }\end{array}$ & $\begin{array}{l}\text { Histological verification } \\
\text { of relapse/refractory } \\
\text { disease after autologous } \\
\text { SCT }\end{array}$ \\
\hline Gentzler et al. [21] (2014) & NR & Nuclear medicine radiologist & Yes (all cases) & NR \\
\hline Nieto et al. [22] (2013) & NR & NR & NR & NR \\
\hline Cocorocchio et al. [23] (2013) & NR & NR & NR & NR \\
\hline Akhtar et al. [24] (2013) & $\begin{array}{l}\text { Stand-alone or hybrid } \\
\text { FDG-PET/CT }\end{array}$ & Two nuclear medicine physicians & $\begin{array}{l}\text { Yes: } 91 \\
\text { No: } 50\end{array}$ & NR \\
\hline Sucak et al. [25] (2011) & Hybrid FDG-PET/CT & Two nuclear medicine physicians & NR & NR \\
\hline Smeltzer et al. [26] (2011) & Hybrid FDG-PET/CT & Two nuclear medicine physicians & NR & NR \\
\hline Mocikova et al. [27] (2011) & $\begin{array}{c}\text { Stand-alone FDG-PET or } \\
\text { hybrid FDG-PET/CT }\end{array}$ & Local nuclear medicine report & Yes (all cases) & NR \\
\hline Arai et al. [28] (2010) & Hybrid FDG-PET/CT & NR & Yes (all cases) & NR \\
\hline Castagna et al. [29] (2009) & Stand-alone FDG-PET & $\begin{array}{l}\text { Experienced nuclear medicine } \\
\text { physician }\end{array}$ & NR & NR \\
\hline Jabbour et al. [30] (2007) & $\begin{array}{l}\text { Stand-alone FDG-PET or } \\
\text { hybrid FDG-PET/CT }\end{array}$ & $\mathrm{NR}$ & Yes (all cases) & NR \\
\hline Schot et al. [31] (2007) & Stand-alone FDG-PET & Two independent reviewers & Yes (all cases) & NR \\
\hline \multicolumn{5}{|c|}{ Pretransplant FDG-PET-adapted therapeutic trials } \\
\hline Moskowitz et al. [32] (2015) & Hybrid PET/CT & Nuclear medicine physician & Yes (all cases) & NR \\
\hline Devillier et al. (2012) [33] & Hybrid PET/CT & Nuclear medicine physician & Yes & NR \\
\hline Moskowitz et al. (2012) [34] & NR & Nuclear medicine physician & Yes (all cases) & NR \\
\hline
\end{tabular}

$N R$ not reported

patients who did not acquire FDG-PET negative status had a worse prognosis $(46$ and $\pm 30 \%,[32,34]$. One retrospective study [33] applied tandem autologous SCT in high-risk patients (where risk was determined on the basis of the pretransplant FDG-PET result and other factors [33]). Patients with pretransplant FDG-PET positive status treated with tandem autologous SCT had a better 5-year PFS (43\%) than those treated with single autologous SCT (0\%), whereas this benefit in terms of 5-year PFS was less clear in those with a negative pretransplant FDG-PET (87 vs. $75 \%$, respectively [33]).

\section{Discussion}

The present systematic review and meta-analysis show that the patients with a pretransplant FDG-PET scan that is positive for residual disease generally have a worse outcome (both in terms of progression-free survival and overall survival) than those with a negative pretransplant FDG-PET scan. The predictive value of pretransplant FDG-PET appears to be moderate, however, with pooled sensitivity and specificity pairs of 67.2 and $70.7 \%$ for the prediction of treatment failure, and 74.4 and $58.0 \%$ for predicting death during follow-up. Since both false-positives and false-negatives are not uncommon, it is questionable whether incorporating pretransplant FDG-PET results in treatment planning in routine clinical practice is justified at this moment.

Several prediction rules have been developed to predict outcome in patients with relapsed/refractory Hodgkin lymphoma undergoing autologous SCT: the Memorial SloanKettering Cancer Center (MSKCC) prognostic model [10], the Grupo Espanol de Linfomas/Trasplante Autologo de Medula Osea (GEL/TAMO) score [4], the Simplified Validated Prognostic Model of the Center for International Blood and Marrow Transplant Research (CIBMTR) [12], and the Adapted Prognostic Score which was developed using the cohort of the HDR2 trial [37]. The MSKCC found the three factors duration of remission $<1$ year, presence of extranodal disease before salvage therapy, and presence of $B$ symptoms before salvage therapy, to be significantly predictive of outcome after autologous SCT [10]. With a median follow-up of 43 months, progression-free survival was $83 \%$ for patients with zero or one risk factor, $27 \%$ for patients with two risk factors, and $10 \%$ for patients with all three risk factors [10]. The GEL/TAMO group identified the following prognostic factors: presence of extranodal disease, chemotherapy refractory disease, and duration of complete remission $<12$ months prior to relapse [4]. Patients with $0-1,2$, and 3 risk factors had long-term progression-free survival rates of 71,51 , and $18 \%$, respectively [4]. The CIBMTR prognostic model [12] found three significant independent predictive 
Table 4 Quality assessment of included studies (risk of bias in six different domains according to the QUIPS tool [16])

\begin{tabular}{|c|c|c|c|c|c|c|}
\hline Study (year) & $\begin{array}{l}\text { Study } \\
\text { participation }\end{array}$ & $\begin{array}{l}\text { Study } \\
\text { attrition }\end{array}$ & $\begin{array}{l}\text { Prognostic } \\
\text { factor } \\
\text { measurement }\end{array}$ & $\begin{array}{l}\text { Outcome } \\
\text { measure }\end{array}$ & $\begin{array}{l}\text { Study } \\
\text { confounding }\end{array}$ & $\begin{array}{l}\text { Statistical } \\
\text { analysis }\end{array}$ \\
\hline Gentzler et al. [21] (2014) & Low & Low & Moderate & Moderate & Moderate & Low \\
\hline Nieto et al. [22] (2013) & Moderate & Low & Moderate & Moderate & Moderate & Low \\
\hline Cocorocchio et al. [23] (2013) & Moderate & Low & Moderate & Moderate & Moderate & Low \\
\hline Akhtar et al. [24] (2013) & Moderate & Low & Moderate & Moderate) & Moderate & Low \\
\hline Sucak et al. [25] (2011) & Moderate & Low & Low & Moderate & Moderate & Low \\
\hline Smeltzer et al. [26] (2011) & Moderate & Low & Low & Moderate & Moderate & Low \\
\hline Mocikova et al. [27] (2011) & Low & Low & High & Moderate & Moderate & Low \\
\hline Arai et al. [28] (2010) & Low & Low & Low & Moderate & Moderate & Low \\
\hline Castagna et al. [29] (2009) & Moderate & Low & Moderate & Moderate & Low & Low \\
\hline Jabbour et al. [30] (2007) & Low & Low & High & Moderate & Moderate & Low \\
\hline Schot et al. [31] (2007) & Low & Low & High & Moderate & Low & Low \\
\hline \multicolumn{7}{|c|}{ Pretransplant FDG-PET-adapted therapeutic trials } \\
\hline Moskowitz et al. [32] (2015) & Low & Low & Low & Moderate & Moderate & Low \\
\hline Devillier et al. (2012) [33] & Low & Low & Low & Moderate & Moderate & Low \\
\hline Moskowitz et al. (2012) [34] & Low & Low & Moderate & Moderate & Moderate & Low \\
\hline
\end{tabular}

factors in the multivariate analysis and developed the following risk score: Karnofsky performance score $<90$ and chemotherapy resistance at autologous SCT were assigned one point, and three or more chemotherapy regimens before autologous SCT and extranodal disease present at autologous SCT were assigned two points. Based on the sum score for the four risk factors, three groups were identified: low ( 0 points), intermediate (1-3 points), or high (4-6 points). The 4 years progression-free survival for the low, intermediate, and high risk groups were 71,60 , and $42 \%$, respectively [12]. Finally, the Adapted Prognostic Score of the HDR2 trial [37] identified the risk factors presence of stage IV at relapse, anemia, and early or multiple relapse. Patients with $0,1,2$, and 3 of these risk factors had a 3-year progression-free survival of approximately $80,70,50$, and $15 \%$, respectively. Future studies are required to compare pretransplant FDG-PET to these clinical risk assessment models and to assess whether the former has any additional value to the latter.

Three prospective studies in which the treatment strategy was based on the pretransplant FDG-PET result have been published. A study by Moskowitz et al. [34] published in 2012 included patients with histologically proven refractory/ relapsed Hodgkin lymphoma who were treated with salvage ifosfamide, carboplatin, etoposide (ICE) chemotherapy. After salvage chemotherapy, patients underwent a restaging FDGPET. Positive scans were defined by site of disease as follows: supradiaphragmatic Hodgkin lymphoma, FDG uptake greater than mediastinal blood pool; and infradiaphragmatic Hodgkin lymphoma, FDG uptake greater than abdominal aortic blood pool. If the FDG-PET scan was negative, patients proceeded to radiotherapy, HDT, and autologous SCT, whereas patients with positive FDG-PET scans were additionally treated with 2 cycles of gemcitabine, vinorelbine and liposomal doxorubicin (GVD), followed by a second restaging FDG-PET scan, radiotherapy, HDT, and autologous SCT. Fifty-eight (60\%) of patients received an FDG-PET based complete response after ICE chemotherapy. Of the remaining 36 patients, 33 were treated with additional GVD, of whom 17 acquired a post GVD negative FDG-PET status. The event-free survivals (EFSs) of patients who achieved a negative FDG-PET after ICE or GVD were almost similar (estimated 4-year EFS approximately $80 \%$ ), whereas those who did not acquire a FDGPET negative status had a worse prognosis (estimated 4-year EFS 28.6\%). Moskowitz et al. [34] concluded that their study provides evidence that the goal of salvage therapy in patients with Hodgkin lymphoma should be a negative FDG-PET scan before HDT and autologous SCT. Unfortunately, their study did not report the effect of their treatment strategy and/or FDG-PET status on the overall survival. Consequently, it still remains unclear whether this treatment strategy will result in a long-term benefit in overall survival. Patients with post HDT and autologous SCT residual disease may have been cured with third-line therapies, thereby relatively decreasing the survival benefit of Moskowitz et al.'s [34] treatment strategy. On top of that, a third-line therapy only exposed the patients in whom second-line therapy failed to additional therapies, and not the entire group of post-salvage FDG-PET positive patients. Of note, 5 of 38 post ICE positive patients became transplant ineligible after the GVD courses, and this number might have been lower when HDT and autologous SCT were applied directly after the ICE/augmented ICE courses. Finally, Moskowitz et al. [34] did not report whether residual disease 


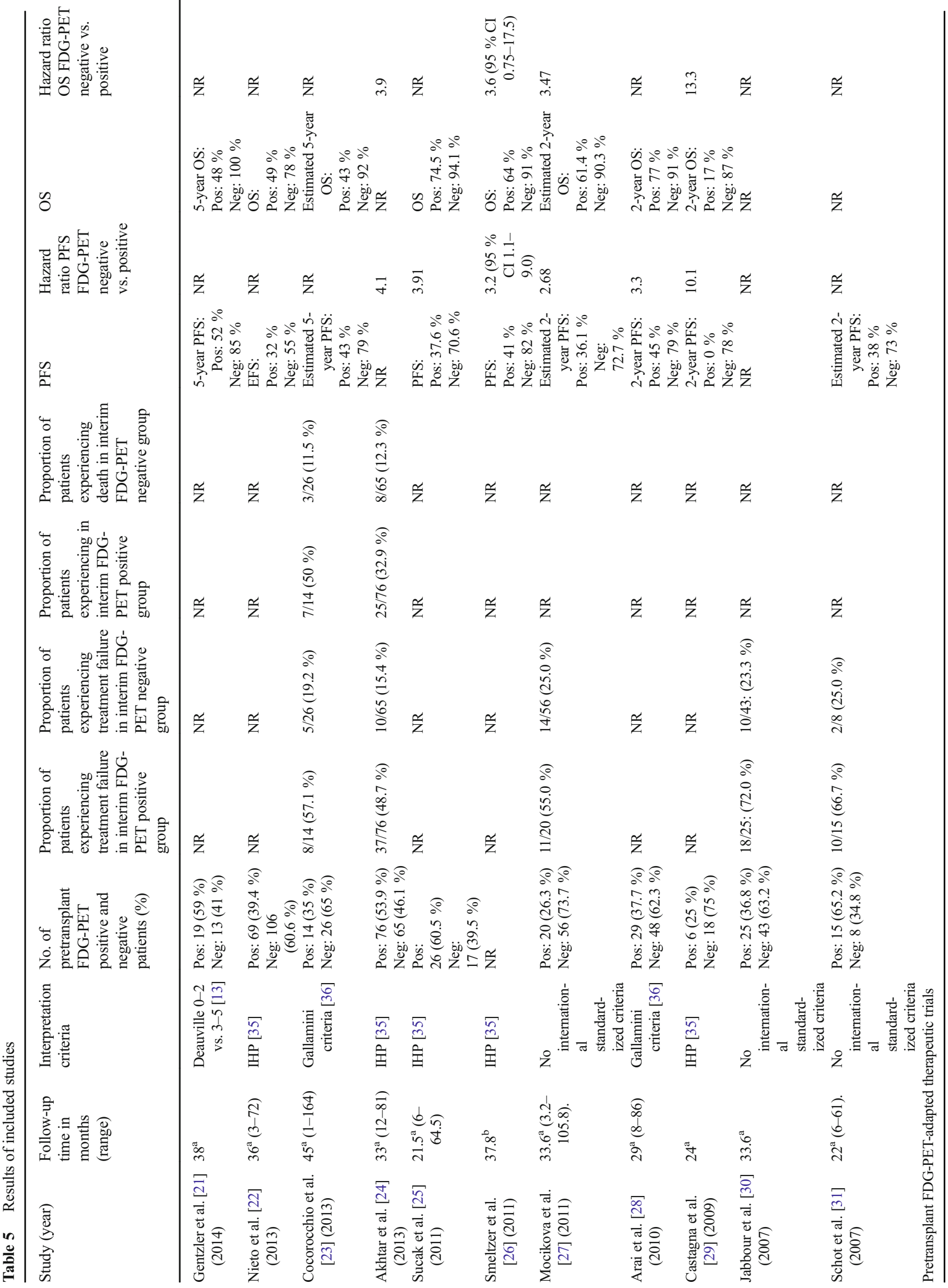




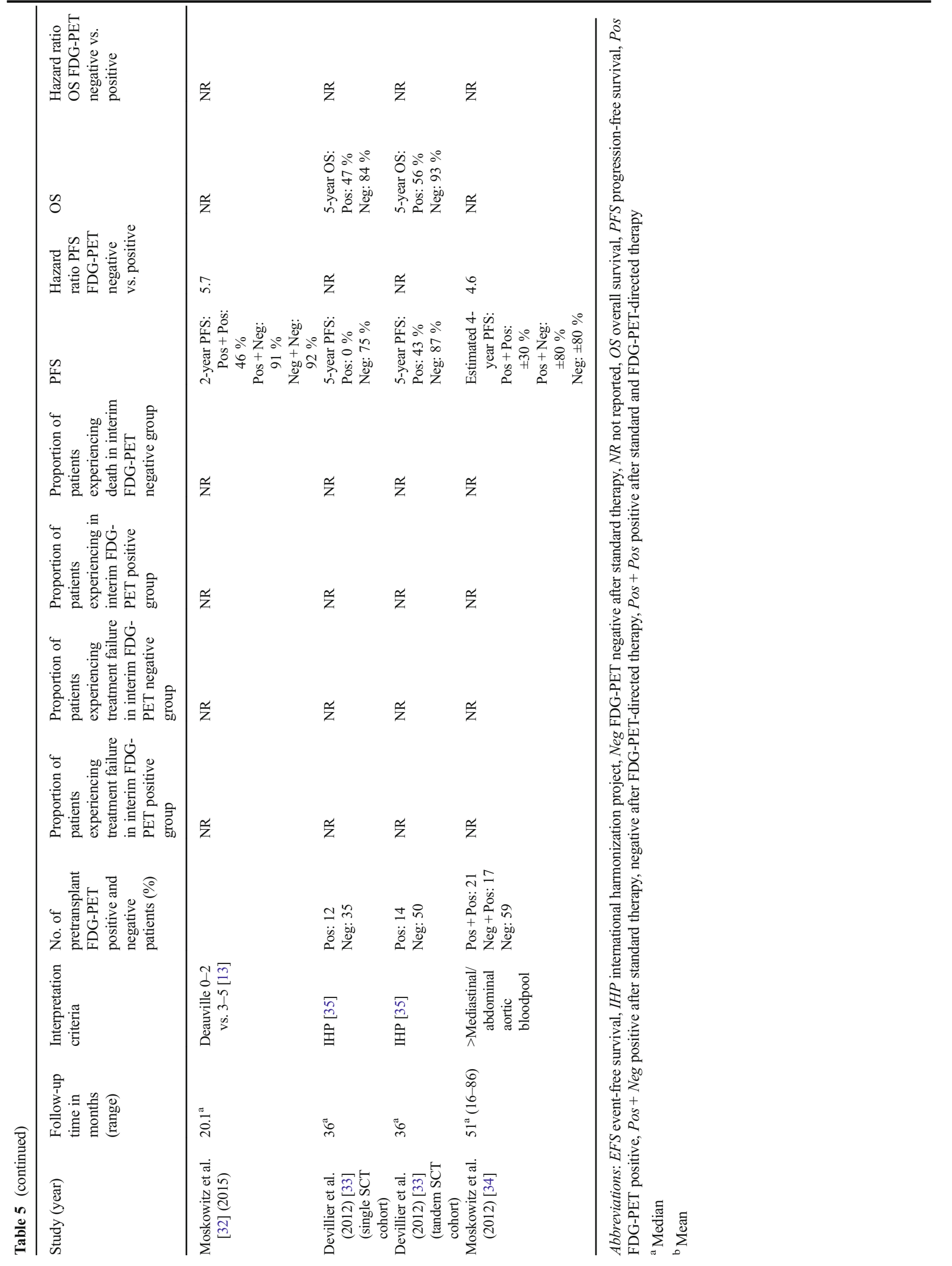


after autologous SCT was histologically verified. Another study by Moskowitz et al. [32] published in 2015 included 45 patients who were treated with 2 cycles of brentuximab vedotin as first-line salvage treatment, followed by an FDGPET scan, which was positive in 33 and negative in 12 patients. Positive patients were treated with second-line salvage therapy by ICE whereas negative patients were directly treated with HDT and autologous SCT. Thirty-two of 33 patients had FDG-PET scans after salvage ICE, of whom 22 were negative and 10 remained positive, followed by HDT and autologous SCT in all 32 cases. The median follow-up was 20 months. At 2 years, EFS of patients who were FDG-PET negative after brentuximab vedotin therapy was $92 \%$, and that of those who were FDG-PET negative after brentuximab vedotin and additional ICE was $91 \%$. Patients who were still FDG-PET positive after brentuximab and vedodotin and ICE had an EFS of $46 \%$. Unfortunately, this study did not report the influence of the FDG-PET status on the overall survival either. Finally, Devillier et al. [33] performed a retrospective analysis of 111 patients with relapsed/refractory Hodgkin lymphoma. Pretransplant FDG-PET status was considered in order to select subsequent therapy by means of either HDT with autologous SCT or tandem HDT with autologous SCT. The choice of single or tandem transplantation was made on the basis of both risk factors (interval from end of first-line therapy to relapse $<12$ months; Ann-Arbor stage III or IV at relapse; and relapse in a previously irradiated field) at relapse and PET response after salvage therapy. After salvage therapy, 85 patients acquired pretransplant FDG-PET negative status, of whom 50 underwent tandem autologous SCT, and 26 acquired pretransplant FDG-PET positive status, of whom 12 underwent tandem autologous SCT. Five-year progression-free survival and overall survival were 75 and $84 \%$ in pretransplant FDGPET negative, and 0 and $47 \%$ in pretransplant positive patients treated with a single HDT and autologous SCT, respectively. On the other hand, 5-year progression-free survival and overall survival were 87 and $93 \%$ in pretransplant negative, and 43 and $56 \%$ in pretransplant FDG-PET positive patients treated with tandem HDT and autologous SCT. In other words, particularly pretransplant FDG-PET positive patients appeared to benefit from tandem HDT and autologous SCT. However, it should be realized that this study included a low number of pretransplant FDG-PET positive patients and that other risk factors were considered in the determination of the treatment strategy. Thus, although the first results of FDG-PET adapted trials are encouraging, the survival benefit of this treatment strategy has not convincingly been proven.

The present systematic review and meta-analysis had several limitations. First, methodological quality of studies included was moderate. Particularly the inter- and intrastudy variability in salvage regimens and number of therapy cycles might have influenced the predictive value of pretransplant FDG-PET. During first-line therapy, the predictive value of interim FDG-PET has already been shown to be influenced by pretreatment risk factors and the treatment regimen that is used [15]. It is not unlikely that these results can be extrapolated to the second-line therapy setting. Second, although studies changing treatment strategy on the basis of the pretransplant FDG-PET result were separated from those who did not apply pretransplant FDG-PET-adapted therapy, it cannot be excluded that some of the included studies might have applied FDG-PET based therapies without clearly describing this in their methodology. Particularly in retrospective studies, the FDG-PET result might have driven clinicians to alter treatment planning (e.g., additional cycles of salvage therapy) and order additional FDG-PET scans before the actual autologous SCT. Third, only five studies reported sufficient data for a meta-analysis on the value of pretransplant FDG-PET in predicting treatment failure, and only two studies reported sufficient data for a meta-analysis on the value of pretransplant FDG-PET in predicting overall survival. Fourth, data on interobserver agreement in FDG-PET interpretation were not reported by individual studies. Interobserver variability of FDG-PET interpretation during therapy (kappa values of 0.66-0.84 have been reported in such settings $[38,39])$ may have affected the results of both individual studies and this meta-analysis.

In conclusion, the moderate quality evidence suggests pretransplant FDG-PET to have value in predicting outcome in refractory/relapsed Hodgkin lymphoma patients treated with autologous SCT. Nevertheless, a considerable proportion of pretransplant FDG-PET positive patients remains disease free and a considerable proportion of pretransplant FDG-PET negative patients develops disease relapse after autologous SCT.

\section{Compliance with ethical standards}

Conflict of interest The authors declare that they have no conflict of interest.

Funding This work was financially supported by an Alpe d'HuZes/ Dutch Cancer Society Bas Mulder Award for T.C.K. (grant number 5409). Data collection, data analysis, and interpretation of data, writing of the paper, and decision to submit were left to the authors' discretion and were not influenced by Alpe d'HuZes/Dutch Cancer Society.

Open Access This article is distributed under the terms of the Creative Commons Attribution 4.0 International License (http:// creativecommons.org/licenses/by/4.0/), which permits unrestricted use, distribution, and reproduction in any medium, provided you give appropriate credit to the original author(s) and the source, provide a link to the Creative Commons license, and indicate if changes were made.

\section{References}

1. Cheson BD (2012) Hodgkin lymphoma: protecting the victims of our success. J Clin Oncol 30(36):4456-4457. doi:10.1200/JCO. 2012.45.5402 
2. Schmitz N, Pfistner B, Sextro M, Sieber M, Carella AM, Haenel M, Boissevain F, Zschaber R, Muller P, Kirchner H, Lohri A, Decker S, Koch B, Hasenclever D, Goldstone AH, Diehl V (2002) Aggressive conventional chemotherapy compared with high-dose chemotherapy with autologous haemopoietic stem-cell transplantation for relapsed chemosensitive Hodgkin's disease: a randomised trial. Lancet 359(9323):2065-2071. doi:10.1016/S0140-6736(02) 08938-9

3. Linch DC, Winfield D, Goldstone AH, Moir D, Hancock B, McMillan A, Chopra R, Milligan D, Hudson GV (1993) Dose intensification with autologous bone-marrow transplantation in relapsed and resistant Hodgkin's disease: results of a BNLI randomised trial. Lancet 341(8852): 1051-1054

4. Sureda A, Constans M, Iriondo A, Arranz R, Caballero MD, Vidal MJ, Petit J, Lopez A, Lahuerta JJ, Carreras E, Garcia-Conde J, Garcia-Larana J, Cabrera R, Jarque I, Carrera D, Garcia-Ruiz JC, Pascual MJ, Rifon J, Moraleda JM, Perez-Equiza K, Albo C, DiazMediavilla J, Torres A, Torres P, Besalduch J, Marin J, Mateos MV, Fernandez-Ranada JM, Sierra J, Conde E (2005) Prognostic factors affecting long-term outcome after stem cell transplantation in Hodgkin's lymphoma autografted after a first relapse. Ann Oncol 16(4):625-633. doi:10.1093/annonc/mdi119

5. Majhail NS, Weisdorf DJ, Defor TE, Miller JS, McGlave PB, Slungaard A, Arora M, Ramsay NK, Orchard PJ, MacMillan ML, Burns LJ (2006) Long-term results of autologous stem cell transplantation for primary refractory or relapsed Hodgkin's lymphoma. Biol Blood Marrow Transplant 12(10):1065-1072. doi:10.1016/j. bbmt.2006.06.006

6. Sirohi B, Cunningham D, Powles R, Murphy F, Arkenau T, Norman A, Oates J, Wotherspoon A, Horwich A (2008) Longterm outcome of autologous stem-cell transplantation in relapsed or refractory Hodgkin's lymphoma. Ann Oncol 19(7):1312-1319. doi:10.1093/annonc/mdn052

7. Moskowitz AJ, Perales MA, Kewalramani T, Yahalom J, CastroMalaspina $\mathrm{H}$, Zhang Z, Vanak J, Zelenetz AD, Moskowitz CH (2009) Outcomes for patients who fail high dose chemoradiotherapy and autologous stem cell rescue for relapsed and primary refractory Hodgkin lymphoma. Br J Haematol 146(2):158-163. doi:10. 1111/j.1365-2141.2009.07727.x

8. Martinez C, Canals C, Sarina B, Alessandrino EP, Karakasis D, Pulsoni A, Sica S, Trneny M, Snowden JA, Kanfer E, Milpied N, Bosi A, Guidi S, de Souza CA, Willemze R, Arranz R, Jebavy L, Hellmann A, Sibon D, Oneto R, Luan JJ, Dreger P, Castagna L, Sureda A (2013) Identification of prognostic factors predicting outcome in Hodgkin's lymphoma patients relapsing after autologous stem cell transplantation. Ann Oncol 24(9):2430-2434. doi:10. 1093/annonc/mdt206

9. Bierman PJ, Lynch JC, Bociek RG, Whalen VL, Kessinger A, Vose JM, Armitage JO (2002) The International Prognostic Factors Project score for advanced Hodgkin's disease is useful for predicting outcome of autologous hematopoietic stem cell transplantation. Ann Oncol 13(9):1370-1377

10. Moskowitz CH, Nimer SD, Zelenetz AD, Trippett T, Hedrick EE, Filippa DA, Louie D, Gonzales M, Walits J, Coady-Lyons N, Qin J, Frank R, Bertino JR, Goy A, Noy A, O’Brien JP, Straus D, Portlock CS, Yahalom J (2001) A 2-step comprehensive high-dose chemoradiotherapy second-line program for relapsed and refractory Hodgkin disease: analysis by intent to treat and development of a prognostic model. Blood 97(3):616-623

11. Josting A, Franklin J, May M, Koch P, Beykirch MK, Heinz J, Rudolph C, Diehl V, Engert A (2002) New prognostic score based on treatment outcome of patients with relapsed Hodgkin's lymphoma registered in the database of the German Hodgkin's lymphoma study group. J Clin Oncol 20(1):221-230

12. Hahn T, McCarthy PL, Carreras J, Zhang MJ, Lazarus HM, Laport GG, Montoto S, Hari PN (2013) Simplified validated prognostic model for progression-free survival after autologous transplantation for hodgkin lymphoma. Biol Blood Marrow Transplant 19(12): 1740-1744. doi:10.1016/j.bbmt.2013.09.018

13. Barrington SF, Mikhaeel NG, Kostakoglu L, Meignan M, Hutchings M, Mueller SP, Schwartz LH, Zucca E, Fisher RI, Trotman J, Hoekstra OS, Hicks RJ, O’Doherty MJ, Hustinx R, Biggi A, Cheson BD (2014) Role of imaging in the staging and response assessment of lymphoma: consensus of the International Conference on Malignant Lymphomas Imaging Working Group. J Clin Oncol 32(27):3048-3058. doi:10.1200/JCO.2013.53.5229

14. Cheson BD, Fisher RI, Barrington SF, Cavalli F, Schwartz LH, Zucca E, Lister TA (2014) Recommendations for initial evaluation, staging, and response assessment of Hodgkin and non-Hodgkin lymphoma: the Lugano classification. J Clin Oncol 32(27):30593068. doi:10.1200/JCO.2013.54.8800

15. Adams HJ, Nievelstein RA, Kwee TC (2015) Prognostic value of interim FDG-PET in Hodgkin lymphoma: systematic review and meta-analysis. Br J Haematol. doi:10.1111/bjh.13441

16. Hayden JA, van der Windt DA, Cartwright JL, Cote P, Bombardier C (2013) Assessing bias in studies of prognostic factors. Ann Intern Med 158(4):280-286. doi:10.7326/0003-4819-158-4-20130219000009

17. Deville WL, Buntinx F, Bouter LM, Montori VM, de Vet HC, van der Windt DA, Bezemer PD (2002) Conducting systematic reviews of diagnostic studies: didactic guidelines. BMC Med Res Methodol 2:9

18. DerSimonian R, Laird N (1986) Meta-analysis in clinical trials. Control Clin Trials 7(3):177-188

19. Higgins JP, Thompson SG, Deeks JJ, Altman DG (2003) Measuring inconsistency in meta-analyses. BMJ 327(7414):557560. doi:10.1136/bmj.327.7414.557

20. Glas AS, Lijmer JG, Prins MH, Bonsel GJ, Bossuyt PM (2003) The diagnostic odds ratio: a single indicator of test performance. J Clin Epidemiol 56(11):1129-1135

21. Gentzler RD, Evens AM, Rademaker AW, Weitner BB, Mittal BB, Dillehay GL, Petrich AM, Altman JK, Frankfurt O, Variakojis D, Singhal S, Mehta J, Williams S, Kaminer L, Gordon LI, Winter JN (2014) F-18 FDG-PET predicts outcomes for patients receiving total lymphoid irradiation and autologous blood stem-cell transplantation for relapsed and refractory Hodgkin lymphoma. Br J Haematol 165(6):793-800. doi:10.1111/bjh.12824

22. Nieto Y, Popat U, Anderlini P, Valdez B, Andersson B, Liu P, Hosing C, Shpall EJ, Alousi A, Kebriaei P, Qazilbash M, Parmar S, Bashir Q, Shah N, Khouri I, Rondon G, Champlin R, Jones RB (2013) Autologous stem cell transplantation for refractory or poorrisk relapsed Hodgkin's lymphoma: effect of the specific high-dose chemotherapy regimen on outcome. Biol Blood Marrow Transplant 19(3):410-417. doi:10.1016/j.bbmt.2012.10.029

23. Cocorocchio E, Peccatori F, Vanazzi A, Piperno G, Calabrese L, Botteri E, Travaini L, Preda L, Martinelli G (2013) High-dose chemotherapy in relapsed or refractory Hodgkin lymphoma patients: a reappraisal of prognostic factors. Hematol Oncol 31(1):34-40. doi: 10.1002/hon.2014

24. Akhtar S, Al-Sugair AS, Abouzied M, Alkadhi Y, Dingle M, Abdelsalam M, Soudy H, Darwish A, Eltigani A, Elhassan TA, Nabil-Ahmed M, Maghfoor I (2013) Pre-transplant FDG-PETbased survival model in relapsed and refractory Hodgkin's lymphoma: outcome after high-dose chemotherapy and auto-SCT. Bone Marrow Transplant 48(12):1530-1536. doi:10.1038/bmt.2013.88

25. Sucak GT, Ozkurt ZN, Suyani E, Yasar DG, Akdemir OU, Aki Z, Yegin ZA, Yagci M, Kapucu OL (2011) Early post-transplantation positron emission tomography in patients with Hodgkin lymphoma is an independent prognostic factor with an impact on overall survival. Ann Hematol 90(11):1329-1336. doi:10.1007/s00277-0111209-0 
26. Smeltzer JP, Cashen AF, Zhang Q, Homb A, Dehdashti F, Abboud CN, Dipersio JF, Stockerl-Goldstein KE, Uy GL, Vij R, Westervelt P, Bartlett NL, Fehniger TA (2011) Prognostic significance of FDGPET in relapsed or refractory classical Hodgkin lymphoma treated with standard salvage chemotherapy and autologous stem cell transplantation. Biol Blood Marrow Transplant 17(11):1646-1652. doi: 10.1016/j.bbmt.2011.04.011

27. Mocikova H, Pytlik R, Markova J, Steinerova K, Kral Z, Belada D, Trnkova M, Trneny M, Koza V, Mayer J, Zak P, Kozak T (2011) Pre-transplant positron emission tomography in patients with relapsed Hodgkin lymphoma. Leuk Lymphoma 52(9):1668-1674. doi:10.3109/10428194.2011.573889

28. Arai S, Letsinger R, Wong RM, Johnston LJ, Laport GG, Lowsky R, Miklos DB, Shizuru JA, Weng WK, Lavori PW, Blume KG, Negrin RS, Horning SJ (2010) Phase I/II trial of GN-BVC, a gemcitabine and vinorelbine-containing conditioning regimen for autologous hematopoietic cell transplantation in recurrent and refractory hodgkin lymphoma. Biol Blood Marrow Transplant 16(8): 1145-1154. doi:10.1016/j.bbmt.2010.02.022

29. Castagna L, Bramanti S, Balzarotti M, Sarina B, Todisco E, Anastasia A, Magagnoli M, Mazza R, Nozza A, Giordano L, Rodari M, Rinifilo E, Chiti A, Santoro A (2009) Predictive value of early $18 \mathrm{~F}$-fluorodeoxyglucose positron emission tomography (FDG-PET) during salvage chemotherapy in relapsing/refractory Hodgkin lymphoma (HL) treated with high-dose chemotherapy. Br J Haematol 145(3):369-372. doi:10.1111/j.1365-2141.2009. 07645.x

30. Jabbour E, Hosing C, Ayers G, Nunez R, Anderlini P, Pro B, Khouri I, Younes A, Hagemeister F, Kwak L, Fayad L (2007) Pretransplant positive positron emission tomography/gallium scans predict poor outcome in patients with recurrent/refractory Hodgkin lymphoma. Cancer 109(12):2481-2489. doi:10.1002/cncr.22714

31. Schot BW, Zijlstra JM, Sluiter WJ, van Imhoff GW, Pruim J, Vaalburg W, Vellenga E (2007) Early FDG-PET assessment in combination with clinical risk scores determines prognosis in recurring lymphoma. Blood 109(2):486-491. doi:10.1182/blood2005-11-006957

32. Moskowitz AJ, Schoder H, Yahalom J, McCall SJ, Fox SY, Gerecitano J, Grewal R, Hamlin PA, Horwitz S, Kobos R, Kumar A, Matasar M, Noy A, Palomba ML, Perales MA, Portlock CS, Sauter C, Shukla N, Steinherz P, Straus D, Trippett T, Younes A, Zelenetz A, Moskowitz CH (2015) PET-adapted sequential salvage therapy with brentuximab vedotin followed by augmented ifosamide, carboplatin, and etoposide for patients with relapsed and refractory Hodgkin's lymphoma: a non-randomised, open-label, single-centre, phase 2 study. Lancet Oncol 16(3):284-292. doi: 10.1016/S1470-2045(15)70013-6
33. Devillier R, Coso D, Castagna L, Brenot Rossi I, Anastasia A, Chiti A, Ivanov V, Schiano JM, Santoro A, Chabannon C, Balzarotti M, Blaise D, Bouabdallah R (2012) Positron emission tomography response at the time of autologous stem cell transplantation predicts outcome of patients with relapsed and/or refractory Hodgkin's lymphoma responding to prior salvage therapy. Haematologica 97(7): 1073-1079. doi:10.3324/haematol.2011.056051

34. Moskowitz CH, Matasar MJ, Zelenetz AD, Nimer SD, Gerecitano J, Hamlin P, Horwitz S, Moskowitz AJ, Noy A, Palomba L, Perales MA, Portlock C, Straus D, Maragulia JC, Schoder H, Yahalom J (2012) Normalization of pre-ASCT, FDG-PET imaging with second-line, non-cross-resistant, chemotherapy programs improves event-free survival in patients with Hodgkin lymphoma. Blood 119(7):1665-1670. doi:10.1182/blood-2011-10-388058

35. Juweid ME, Stroobants S, Hoekstra OS, Mottaghy FM, Dietlein M, Guermazi A, Wiseman GA, Kostakoglu L, Scheidhauer K, Buck A, Naumann R, Spaepen K, Hicks RJ, Weber WA, Reske SN, Schwaiger M, Schwartz LH, Zijlstra JM, Siegel BA, Cheson BD (2007) Use of positron emission tomography for response assessment of lymphoma: consensus of the Imaging Subcommittee of International Harmonization Project in Lymphoma. J Clin Oncol 25(5):571-578. doi:10.1200/JCO.2006.08.2305

36. Gallamini A, Hutchings M, Rigacci L, Specht L, Merli F, Hansen M, Patti C, Loft A, Di Raimondo F, D’Amore F, Biggi A, Vitolo U, Stelitano C, Sancetta R, Trentin L, Luminari S, Iannitto E, Viviani S, Pierri I, Levis A (2007) Early interim 2-[18F]fluoro-2-deoxy-Dglucose positron emission tomography is prognostically superior to international prognostic score in advanced-stage Hodgkin's lymphoma: a report from a joint Italian-Danish study. J Clin Oncol 25(24):3746-3752. doi:10.1200/JCO.2007.11.6525

37. Josting A, Muller H, Borchmann P, Baars JW, Metzner B, Dohner H, Aurer I, Smardova L, Fischer T, Niederwieser D, Schafer-Eckart K, Schmitz N, Sureda A, Glossmann J, Diehl V, DeJong D, Hansmann ML, Raemaekers J, Engert A (2010) Dose intensity of chemotherapy in patients with relapsed Hodgkin's lymphoma. J Clin Oncol 28(34):5074-5080. doi:10.1200/JCO.2010.30.5771

38. Biggi A, Gallamini A, Chauvie S, Hutchings M, Kostakoglu L, Gregianin M, Meignan M, Malkowski B, Hofman MS, Barrington SF (2013) International validation study for interim PET in ABVD-treated, advanced-stage hodgkin lymphoma: interpretation criteria and concordance rate among reviewers. J Nucl Med 54(5):683-690. doi:10.2967/jnumed.112.110890

39. Itti E, Meignan M, Berriolo-Riedinger A, Biggi A, Cashen AF, Vera P, Tilly H, Siegel BA, Gallamini A, Casasnovas RO, Haioun C (2013) An international confirmatory study of the prognostic value of early PET/CT in diffuse large B-cell lymphoma: comparison between Deauville criteria and DeltaSUVmax. Eur J Nucl Med Mol Imaging 40(9):1312-1320. doi:10.1007/s00259-013-2435-6 